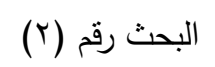

دور القتون الابداعية في استعادة الصحة النفسية والعقلية للمرضى من وجهة نظر المُعالجين بالفن: دراسة تجريبية

THE ROLE OF CREATIVE ARTS IN PSYCHOLOGICAL AND MENTAL HEALTH RECOVERY FROM ART THERAPIST'S PERSPECTIVE: EMPIRICAL STUDY

$$
\text { أ.د / بسـام ناصر الردايـدة }
$$

قسـم التصميـم والقنون التطبيقيـة، كلية القــون الجميلـة

$$
\text { جامعة اليرمول، إربد - الأردن }
$$


تم إجراء هذه الدراسة باستخدام مقابلات شخصية مفتوحة متعقة لثلاثة من المعالجين بالفن ومن ذوي الخبرات بالتطبيقات الفنية بهدف استكثاف وجهات نظرهم حول مدى مساهمة الفن في استعادة الصحة النفسية والعقلية. لقد نم اختبار المعالجون من ثلاثة مراكز صحة نفسية من احدى الدول العربية. وقد تم استخدام المنهج التحليلي الوصفي لتفسير نصوص المقابلة بالإضافة الى تجميع المفاهيم والأفكار الرئيسية وتقسيمها الى ثلاث مجموعات. المجموعة الأولى ركزت على توضيح كيف ساهدت مهارات المُعالج بالفنون في العلاج النفسي والعقلي. بينما المجموعة الثانية ركزت على التغيرات الداخلية للمريض اثثاء ممارسة الفنون التطبيقية. أما المجموعة الثالثة فقد حددت فوائد اجتماعية أوسع للفن. لقد أظهرت النتائج استكثافًا اوليا عميقا للمعارف الناتجة عن تجارب المعُالج بالفن، وتسليط الضوء على المهارات والكفايات اللازمة التي يجب توفرها عند الكُعالجون الذين يتعاملون مع البرامج والأنشطة الفنية والتربوية العلاجية ضمن سياقات استعادة الصحة النفسية والعقلية. قد تساعد هذه البيانات في تعديل سياسات استعادة الصحة النفسية والعقلية وتصميم برامج وأنشطة فنية علاجية، بالإضافة الى توفير أساس لإجراء مزيد من البحوث حول دور الممارسات الفنية في تعافي الصحة النفسية والعقلية.

الكلمات الادالة: العلاج بالفن، الفنون الابداعية، المُعالج بالفن، إعادة التأهيل النفسي والعقلي. 
THE ROLE OF CREATIVE ARTS IN PSYCHOLOGICAL AND MENTAL HEALTH RECOVERY FROM ART THERAPIST'S PERSPECTIVE: EMPIRICAL STUDY Bassam N. Al-Radaideh, Associate Professor

Department of Design and Applied Arts, College of Fine Arts Yarmouk University, Irbid-Jordan

\begin{abstract}
:
This study was conducted using in-depth, open-ended interviews of three art therapists with expertise in art applications to discuss their points of view about the contribution of art-making on mental health restoration. Therapists were selected from three different mental health centers from one of the Arab countries; those centers were involved in various art-making programs. The descriptive-analytical method was used to interpret and analyze the interview transcripts in addition to grouping the main concepts and ideas and divide them into three groups. The first group focused on explaining how the art therapist's skills and qualities contributed to psychotherapy. The second grouping focused on the internal changes of the patient during the arts practices. The third group identified broader social benefits for art. The results show a profound initial exploration of the knowledge generated by the art therapist's experiences and practice. It also highlights the skills and competencies needed for those therapists dealing with therapeutic, educational programs within mental health restoration contexts. Those data may help to modify mental health restoration policies, and help to design therapeutic, technical programs, as well as provide a basis for further research into the role of art education practices in mental health recovery.
\end{abstract}

Keywords: art therapy, art-making, creative arts, art therapist, psychological, and mental health recovery. 


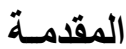

لقد عزز ظهور استعادة الصحة العقلية عند المرضى في التسعينيات من القرن

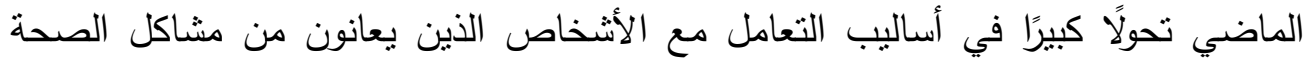
العقلية المزمنة. وقد شجعت فلسفة الاستشفاء مهنيي الصحة العقلية وصانعي السياسات ومقدمي الخدمات النفسية على إعادة تقييم الممارسات الحالية التي يتبعها الخبراء ودمج معارف وخبرات المرضى حول مرضهم واحتياجاتهم في التخطيط لخدمات الصحة النفسية.

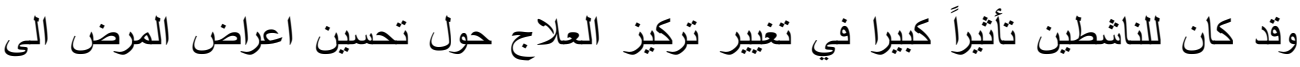

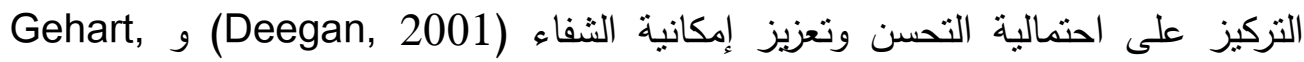
(2012). لقد عرّف دعاة إعادة التأهيل بأنها عملية صعبة للنمو الثخصي والتي تتضمن تطوير الثعور بهدف المرءء من الحياة مع تجاوز الأعراض والإعاقة العقلية والخجل. وقد أبرز ديجان Deegan فكرة أن إعادة التأهيل العقلي والنفسي هو رحلة للثفاء وليس كوجهة

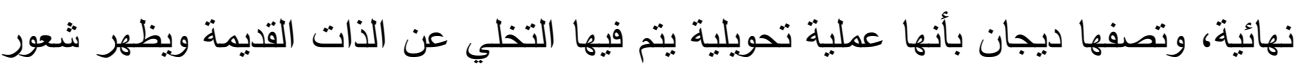

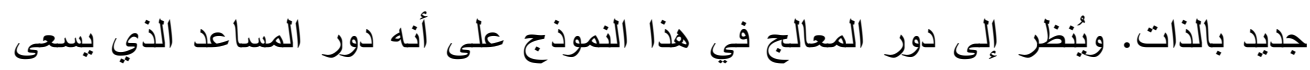
إلى دعم المرضى نحو بناء المهارات والثعور بالقوة من أجل أن يصبح ذاتي التحكم بنفسه بدلاً من الامتثال لغيره (Deegan, 2001).

وقد يُنظر إلى نظام الثفاء الآن على أنه الروئية الإرشادية لخدمات الصحة العقلية المعاصرة (2014) Hyde., Bowles, \& Pawar. ومع ذللك، فقد كان من الصعب نطوير

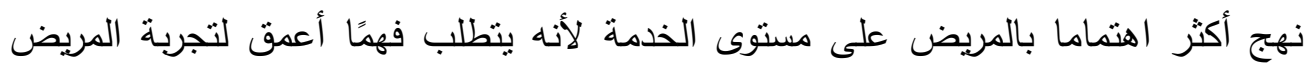
ودور الأنشطة في إعادة تأهيله (Khoury, 2018 ).

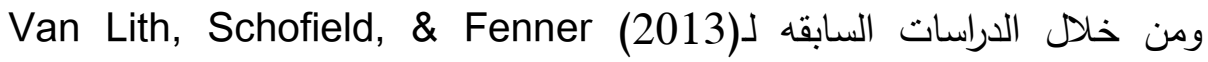

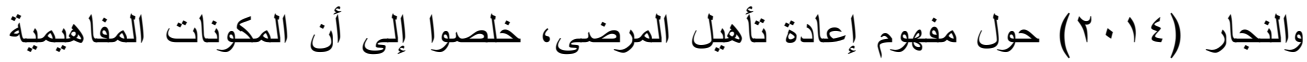

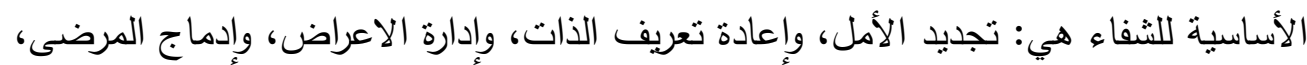
والمشاركة في أنشطة هادفة، والتغلب على الخجل، والتمكين، وممارسة المواطنة والادارة

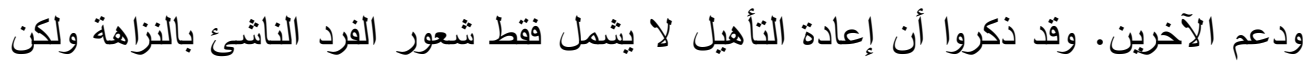

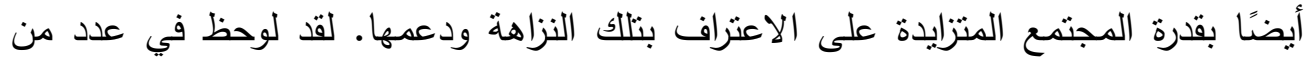
الدول الغربية ان خدمات إعادة التأهيل النفسي والاجتماعي هي المحرك الرئيسي في تعزيز 
إعادة التأهيل والممارسات المبتكرة لمساعدة المرضى على استعادة الصحة العقلية.

(Ramon, Healy, \& Renouf 2007)

لقد كانت أنشطة الفنون الابداعية والممارسات الفنية المبتكرة عنصرا محورياً في إعدادات الخدمة النفسية والاجتماعبة؛ ومع ذللك، كانت الدراسات والبحوث التي تبحث عن دور الفنون في المعالجة الصحية والعقلية لدى المرضى محددة. لقد اشتملت الممارسات الفنية

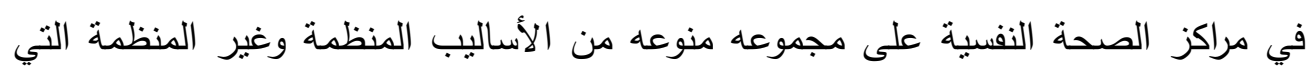
تتوافق مع الممارسات والانشطة المستمرة للمرضى. وتتشنمل هذه الأنشطة على الممارسات

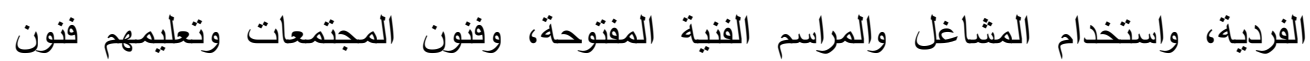
تطبيقية متتوعة، ومتابعتهم وعلاجهم بواسطة الفنون(Zeilig, Killick, \& Fox, 2014).

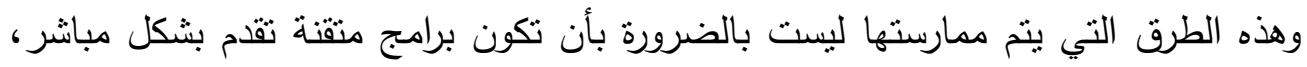

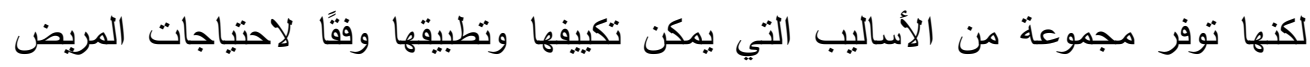

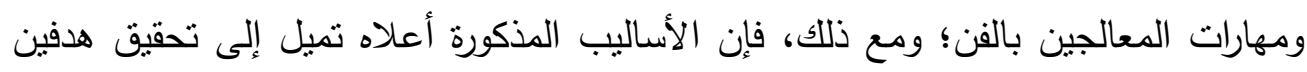
أساسيين هما: التمكين الثخصي والعلاج بالفن .يشير التمكين الثخصي إلى بلى تطوير الاستقلال الذاتي والتحفيز الذاتي. وفي هذا السياق يشير الهدف العلاجي الي الأنشطة الفنية

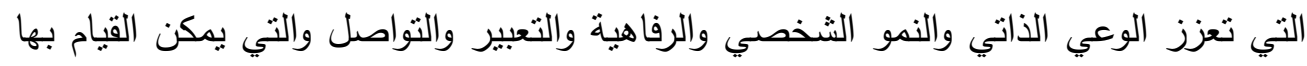
بمفردها، أو ضمن مجموعات بحضور المعالج الفني أو بدونه (Li \& Wang, 2016). لقد كُتب الكثير من المقالات والابحاث حول أهمية الفنون الابداعية للفرد في العلاج

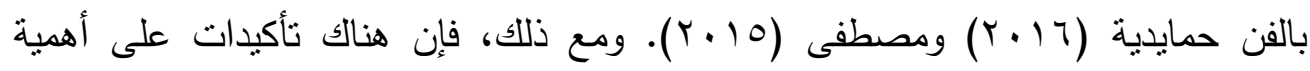
ممارسة الفنون وإمكانية نطبيقها على نطاق أوسع وتتاول الأساليب الاجتماعية والمهنية

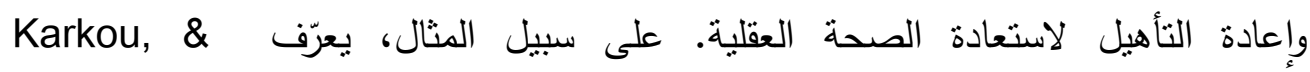
(العلاج بالفن كاكتثاف روابط جديدة وعلاقات جديدة ومعاني جديدة في جو آمن وغير خاضع للحكم، مما يوفر للمريض وجهات نظر بديلة عن حياتهم وطريقة

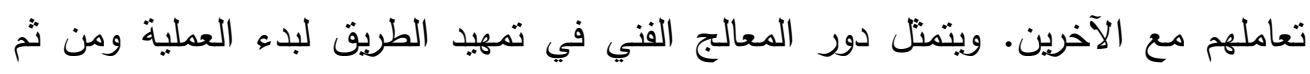
تسهيل استمرار العملية.

يستخدم مصطلح "المُعالج الفني" في هذه الدراسة كمصطلح عام ليشمل الأدوار

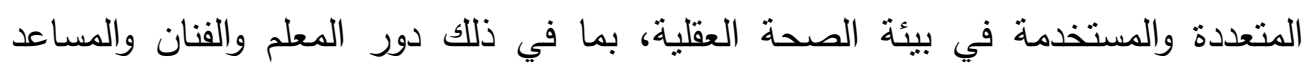
النفسي والاجتماعي والذي يتمتع بالمهارات الفنية. ويُنظر إلى التتوع في الأدوار وفهمها على دلى دلى 
أنه يعمل جنبًا إلى جنب وبصورة نتاركية، وقد يتحول شخص واحد الى اثثين أو أكثر في ممارستهم للتطبيقات. وقد أثنارت Allen (1 . . . وهي باحثة وممارسة ولها خبرة في مجال العلاج بالفن، إلى أن انتاج الفن في البيئات النفسية والاجتماعية هي عملية لمعرفة الذات.

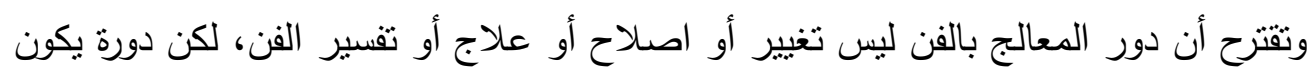

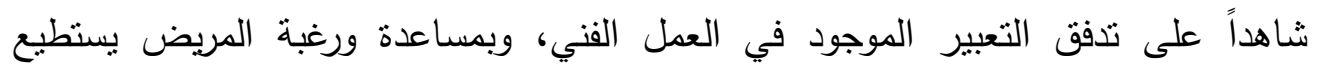
اكتشاف المعنى الكامن من وراء العمل الفني. وبالتالي، فإن التحول يحدث من خلال التوجيه الذاتي ككثف طبيعي لواقع الفنان (المريض)، ومن خلال التعبير، وكلما تعرّف المرضى منى

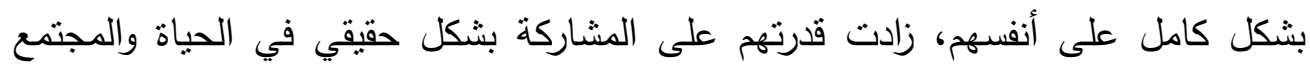
بالإضافة إلى تطور مستمر نحو الثفاء.

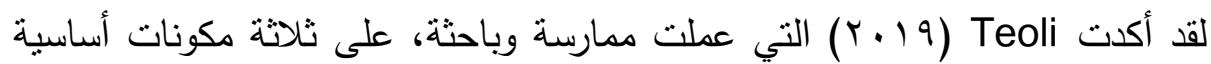

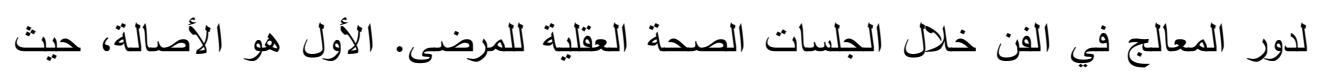

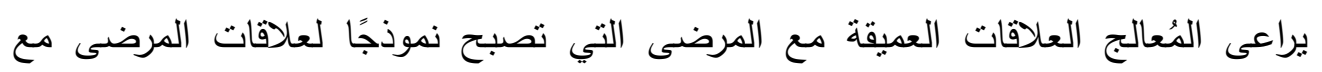

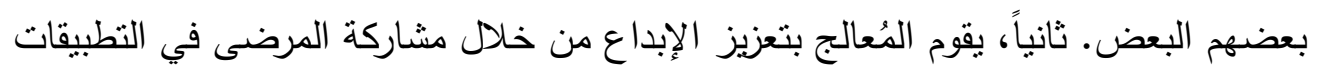

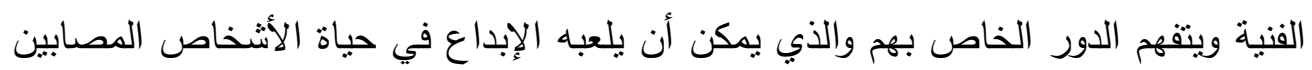

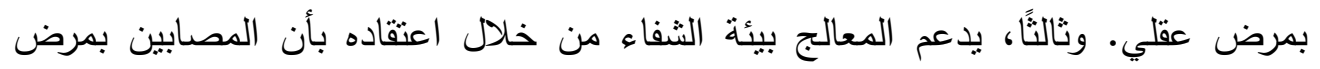

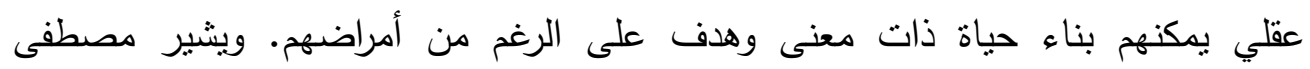

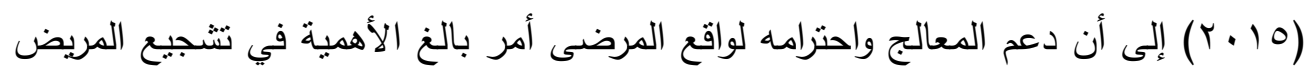

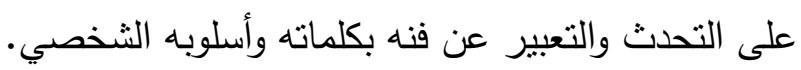

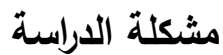

لقد حددت الدراسات السابقة التي تتاولت وجهة نظر المرضى العوامل الرئيسية التي تعمل بمثابة منصة وتوجهنا لفهم ظاهرة العلاج بالفن. Lloyd, Wong, \& Petchkovsky

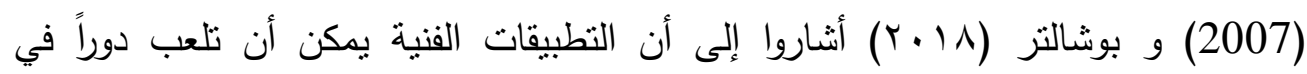

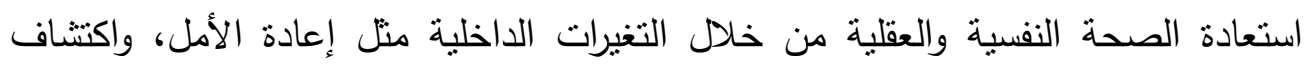

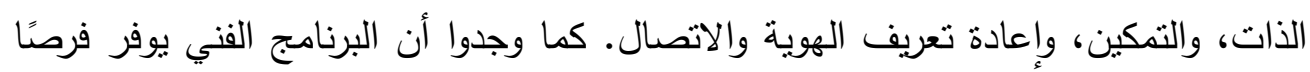
للاستكثاف والإدماج الاجتماعي والدعم المستمر للتعافي. لقد ساهمت هذه المجموعة الناشئة

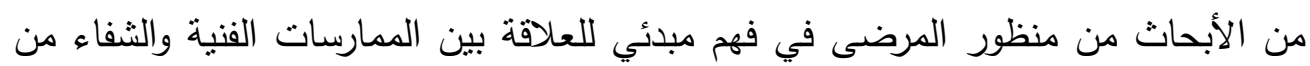


الامراض النفسية. حتى الآن، كان هناك القليل من الأبحاث من منظور معالجي الفن، على الرغم من احتمال أن معالج الفن قد يكون له أو لها نظرة قيمة في هذه الابحان الظاهرة كثهود يقدمون التوجيه والرعاية بهدف علاج المرضى.

\section{أسئلة الدراسـة}

1. ما إمكانية تحسين الصحة النفسية والعقلية عند المرضى من خلال الفنون الابداعية من

وجهة نظر المُعالجين بالفن؟

r. ما دور المُعالج بالفن خلال الجلسات الفنبة العلاجية؟ بالهن

\section{أهداف الاراسـة}

تهدف هذه الدراسة إلى:

تسليط الضوء والحصول على فهم عميق حول مساهمة الفنون الابداعية في امكانية علاج وتحسين الصـحة النفسية للمرضسى وذلك مـن منظور المعـالجين بـالفن وتجـاربهم وخبراتهم

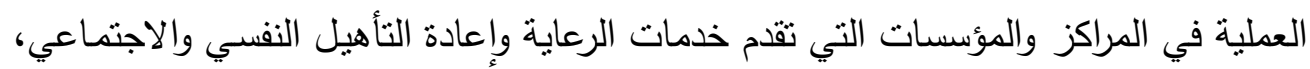
ومن هذه الأهداف: ا ـ توضيح الدور الذي يقوم به المعالج بالفن في تتمية المهارات العقلية لدى المرضى.

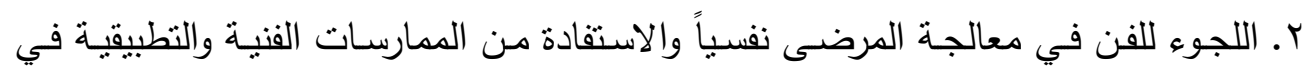
تحسين مزاج المريض.

\section{أهمية الدراسـة}

تعد هذه الدراسة من الدراسات التي اعتمدت بمنهجها التجريبي على المقابلات الثخصية

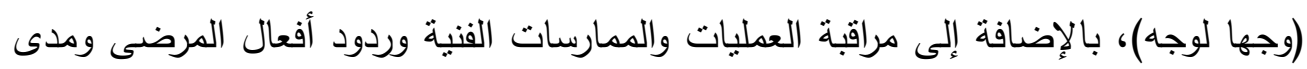
تطبيق البرنامج العلاجي والوقوف على نتائجه. أضف إلى ذلى ذلك اثراء الجانب التنظيري

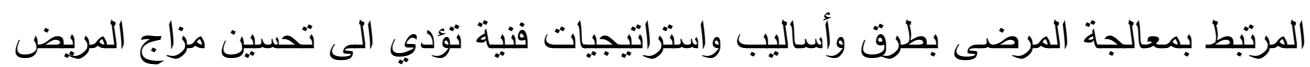
وصولا الى الثفاء. 


\section{مفاهيـم الاراسـة}

الصحة النفسية والعقلية: يعّد مفهوم الصحة النفسيةMental Health من المصطلحات المرتبطة بالطب النفسي، وقد ورد مصطلح الصحة العقلية Mental hygiene لأول مرة في مند وني عام 19.1 في كتاب "عقل قد وجد نفسه" Amind that Found it Self للمؤلفه كليفورد بيرز Clifford Beers. ثم انتقل هذا المصطلح إلى اللغة الألمانية، إلا أنه تغير الى الصحة النفسية Psycho Hygience باعتبار أن هذا التغير قد تجاوز علاج العقول إلى علاج النفوس. وفي عام 19 1 قامت منظمة الصحة العالمية بتعريف الصحة النفسية كالتالي: "الصحة النفسية تعد حالة من السعادة الكاملة من الناحية الجسمية والعقلية والاجتماعية Bertolote, "بحيث ارتبطت ارتباطاً وثيقا بتكيف الفرد مع ذاته ومحيطه الداخلي والخارجي لهنه J. (2008)

American ( المرض النفسي: تعرّف الرابطة الأمريكية للطب النفسي (T)

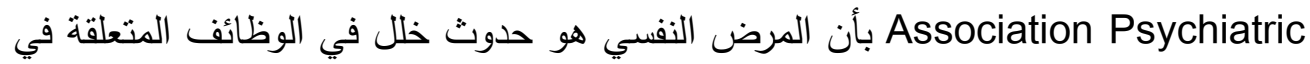
شخصية الإنسان، ويحدث هذا نتيجة لحدوث انحراف عن السواء، وفي هذه الحالة يصاب

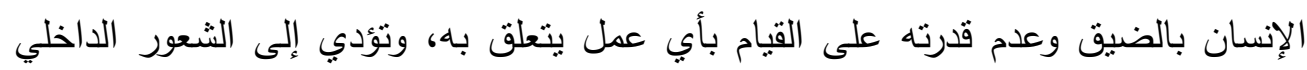
لدى الثخص بأنه يكره نفسه ولا ينقبلها.

العلاج بالفن: حسب تعريف الجمعية الأمريكية للعلاج بالفن، فانه علاج باستخدام الفنون

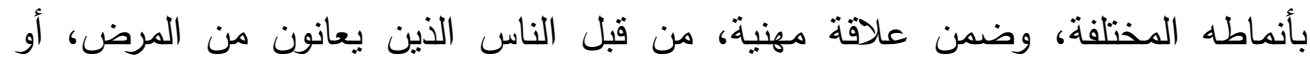

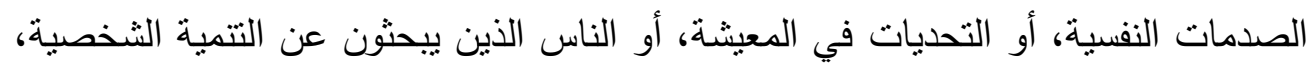
من خلال خلق الفن وانعكاس آثاره على المنتجات والعمليات التي يؤودنها، ويمكن ان بستخدم زيادة الوعي الذاتي، والتعامل مع الاعراض والاجهاد، والتجارب المؤلمة، وتعزيز القدرات المعرفية، والتمتع بمباهج الحياة (Malchiodi, 2003). المُعالج بالفن: وهو خبير ومختص في معالجة الامراض النفسية والعقلية باستخدام الفنون الإبداعية ودوره يتلخص في استبدال الثحنات السلبية عند المريض النفسي والعقلي بشحنات إيجابية وذلك من خلال الممارسات الفنية المتتوعة التي يتعلمها المريض من المُعالج بهدف

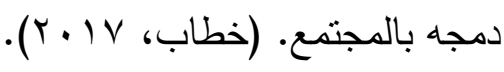


أما إجرائيا: فيعرفه الباحث بأنه المعلم أو المرشد المتخصص بالعلاج بالفن والذي يحمل

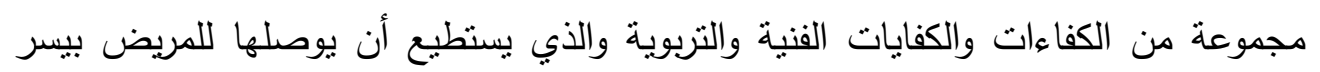

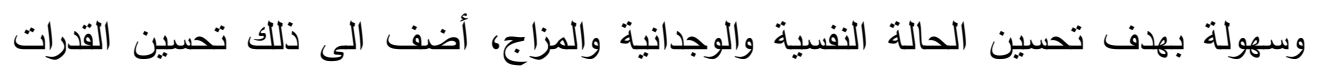
العقلية والمهارية من خلال ممارسة المهارات والتطبيقات الفنية.

الفنون الابداعية: هي تللك المرتبطة بإنتاج اعمال فنيه معبرة متصفة بالجمال والوظيفة وهي

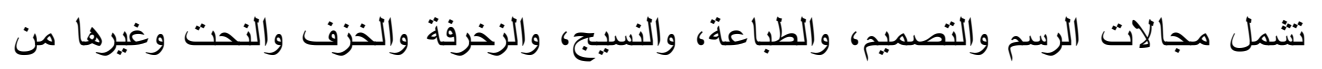
الاشغال والاعمال الفنية.

\section{منهجيـة البحث}

لقد استخدمت الدراسة طريقة المقابلات المفتوحة بهدف استتباط أكبر قدر ممكن من المعلومات المتعلقة بالعلاج النفسي وآراء وخبرات المعالجين حول دور الانشطة الفنية في

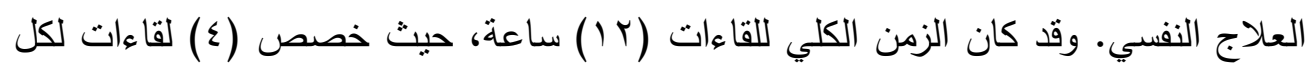
معالج وكانت الفترة الزمنية للمقابلة الواحدة تستغرق ساعة واحدة. وقد كانت اللقاءات تتم في أماكن عمل المعالجون في مُؤسسات الصحة النفسية، بالإضافة الى تسجيل المقابلات

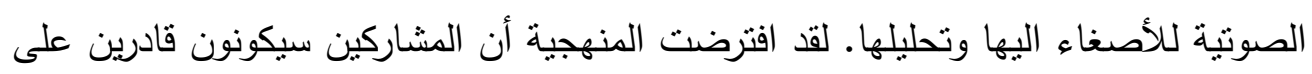
إعطاء رؤى حقيقية وموثوقة من تجاربهم العاطفية والمعرفية في تسهيل عمل الفنون الابداعية

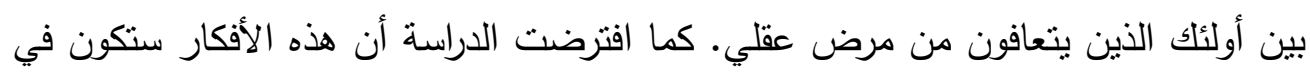

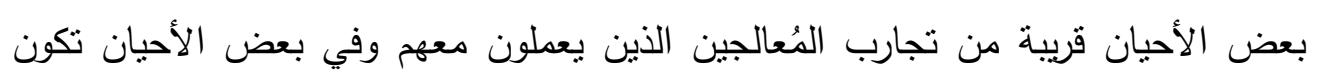

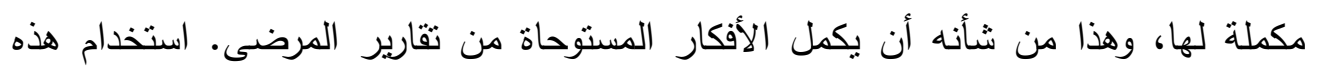
المنهجية في البحث الحالي يتماثى مع الدعوة إلى استخدام أساليب جديده في الأبحاث التي لتئي

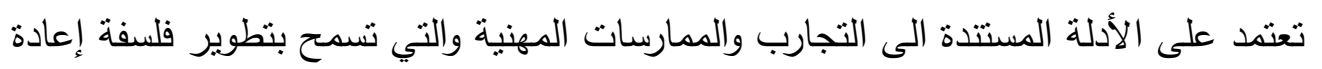
التأهيل والاضافة اليها. لقد أجريت الدراسة في ثلاثة مراكز للصحة النفسية والعقلية في احدى الدول العربية

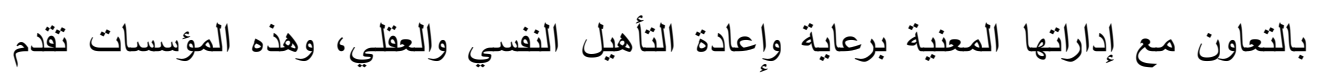
مجموعه منتوعة من البرامج والفنون المختلفة كجزء من خدماتها. واستجابة لاحتياجات 
المريض لمزيد من أساليب إعادة التأهيل الداعمة له، تم تطوير اساليب مبتكره ومنتوعة للعلاج النفسي امتازت بالمبادئ التالية: (1) تقديم أنشطة فنية لتنمية المهارات ومساعدتهم على العمل في بيئتهم. (Y) رعاية المرضى وإعادة تعريف إحساسهم بالذات.

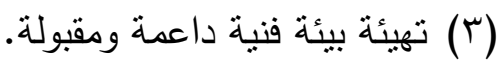

تعزيز العلاقات فيما بينهما.

لقد وُجدَ أن الفنون الابداعية يمكن ممارستها على شكل سلسلة من الانشطة الفنية

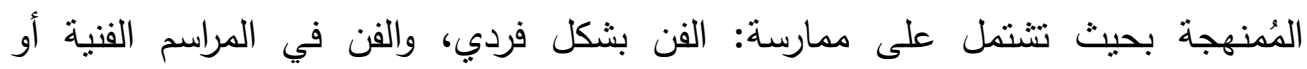

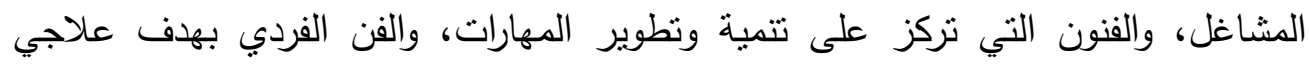

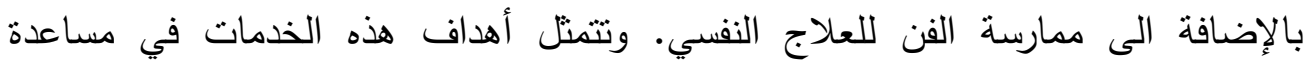

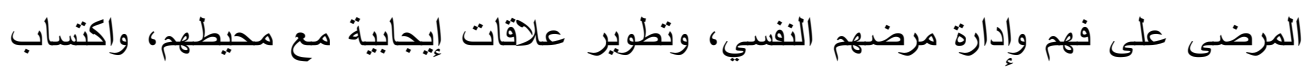
المهارات التي تساعدهم في بناء نمط حياة مستقل ضمن بيئة آمنة وداعمة لهم. هذه البرامج تتبنى العمل بشكل شمولي بحيث تعمل على تطوير جميع مجالات التتمية الثخصية، بما في

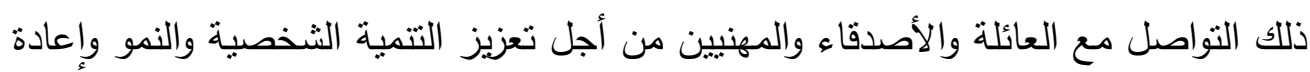
التأهيل خلال اقامتهم في المصحات العقلية لمدة عامين.

المشاركيـن

لقد تم اختيار ثلاثة من المعالجون بالفنون الابداعية للمشاركة في هذه الدراسة وهم من أصحاب الخبرات، حيث عملوا في ثلاثة برامج فنية مختلفة وفي ثناث مُؤسسات للصحة

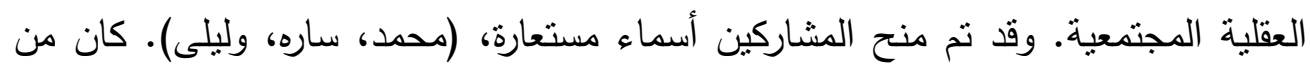
الضروري استخدام المصطلح العام "المُعالج بالفن" ليشمل خلفياتهم المختلفة وألقابهم الوظيفية.

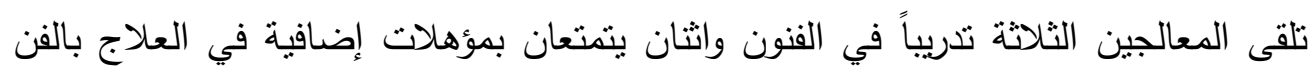

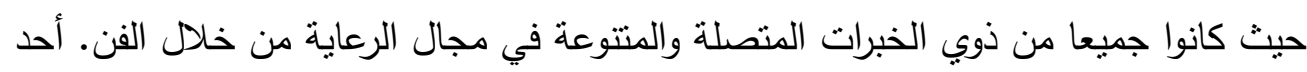
المشاركين كان قائد لفريقه في العلاج النفسي، والثاني كان يعمل كداعم نفسي واجتماعي، أما

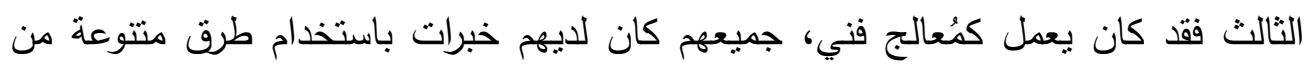

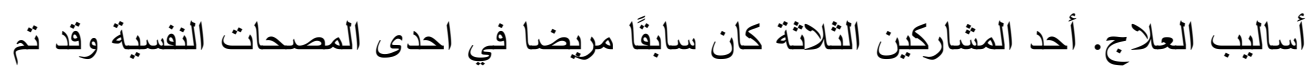
علاجه وشفاؤه من مرضده. كان يُنظر إلى حجم العينة على أنها مقبولة ومناسبه لمشروع 
تجريبي مصمم بهذف الحصول على روايات ومعلومات غنية وقيمة عن تجارب المعالجين بالفن في مراكز الصحة النفسية.

\section{جــع البيانـات}

لقد نم جمع البيانات من خلال مقابلات مباشرة شبه منظمة ووجها لوجه، وقد كانت طبيعة الاسئلة مفتوحة بهدف الحصول على أكبر قدر ممكن من المعلومات وردود الافعال. وقد تم تصميم المقابلات لتوجيه المشارك نحو تجربته كمعالج دون تحديد مُسبق لمحتوى التفاعل. لقد ركزت الأسئلة حول الكثف عن نظرة المعالجون الى العلاقة بين الأنشطة الفنية

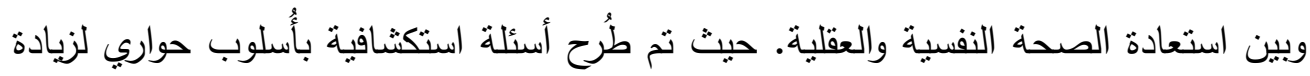
الاستكثاف أو توضيح جوانب معينة من ردود أفعال المشاركين.

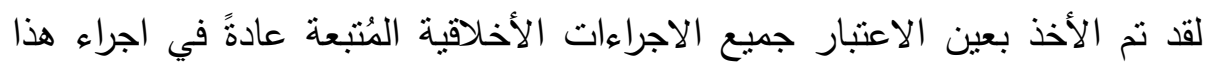

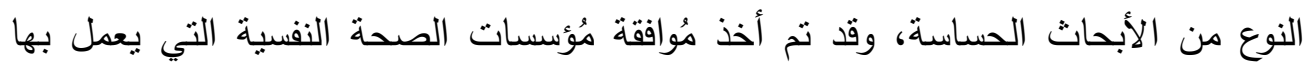
المشاركون في هذه الدراسة. مُنح المشاركين الفرصة لطرح الأسئلة والاستفسارات قبل وخلال المقابلة، ونم تأكيد عدم الكثف عن هويتهما وحقهم في الانسحاب من الدراسة وتأمين الحفاظ

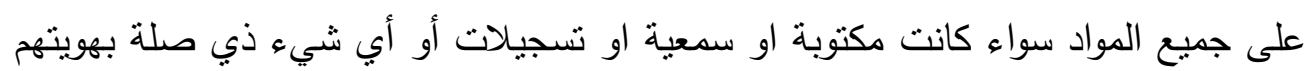

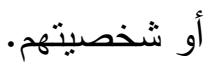

\section{تحليل البيانـات}

تم تحليل البيانات باستخدام نهج توضيحي تفسيري للكثف عن الموضوعات المركزية والمشتركة من تجارب المشاركين، وكذلك لتسليط الضوء على الفروق الفردية. وقد تمت قراءة البيانات المكتوبة عدداً من المرات للتأكد ولاستتباط المفاهيم الأساسية والعبارات والمفاهيم

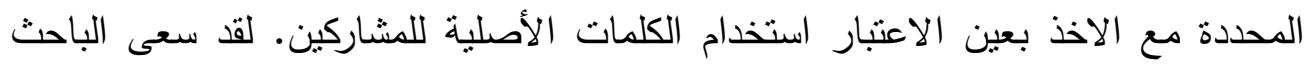

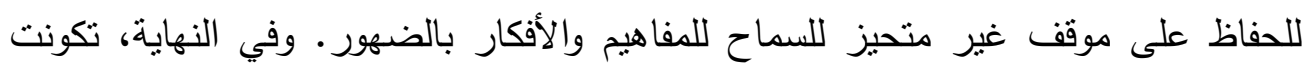

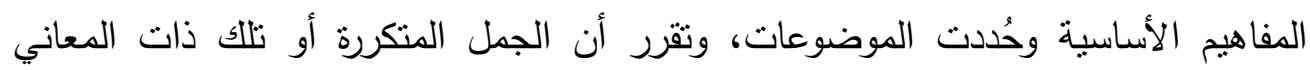

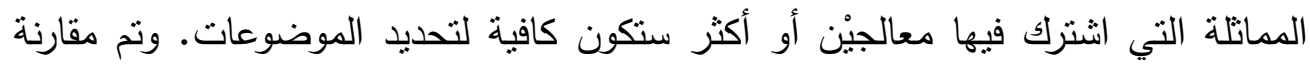

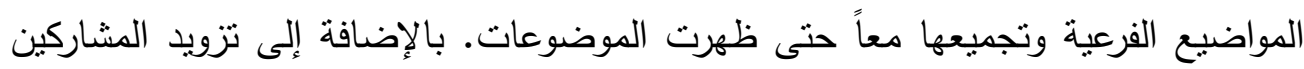

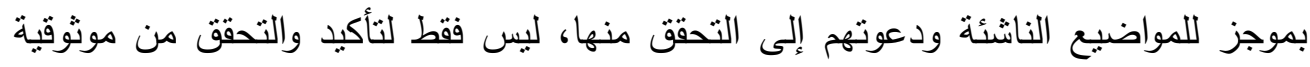


الموضوعات ولكن أيضًا للتعرف على الجهة التي يتحدث الباحث بالنيابة عنها. جميع الإجراءات التي نم اتخاذها في جمع وتحليل البيانات ساهدت في تقوية وتأكيد مصداقية

من خلال عملية التعمق في قراءة نصوص المقابلة وتحليلها، ظهر ثمانية موضوعات

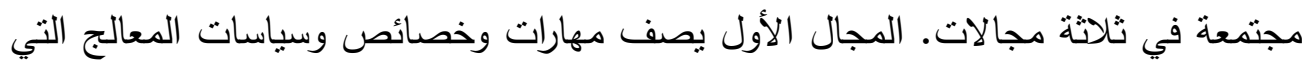
شوهدت لتسهيل الثفاء بالفن. هذه تصف أهمية نية المعالج ودوره في خلق بيئة وتجربة ذات معنى لعلاج المرضى. المجال الثاني حدد عددًا من الطرق التي استطاع بها مُمارسة الفن بهن تزويد المرضى بتجربة تحويلية ايجابية. اما المجال الثالث فهو مجال رئيسي لوصف لدور

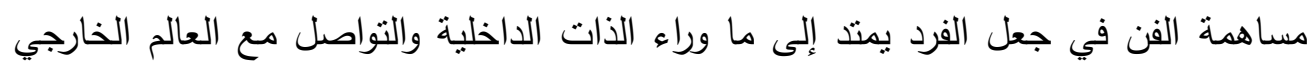
الأوسع. ولقد تم توضيح الموضوعات الثمانية ضمن المجالات الثناثة في القسم التالي.

\section{ا ـصفـات ونهـجـ المُعالـج بالفـن}

\section{ايمان المُعالج بقدرة المريض الابداعية}

بالنسبة للمعالج عملية شفاء المريض وتجاوزه لأعراض المرض تضمنت التعامل مع المبه المريض متجاوزاً مرضه وتقدير ارادته وشجاعته وذكاءه. ولقد كان تقدير القدرات الإبداعية

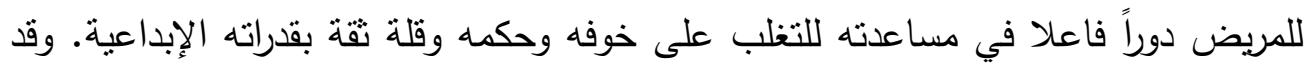
رأي المعالج أن دوره هو الايمان بسعي المريض لإيجاد معنى لحياتهم من خلال ممارسة

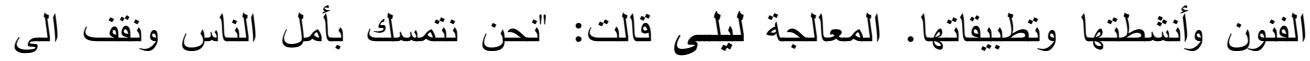
جانبهم ونقدم لهم كل ما يلزم حتى يتمكنوا من استعادة ارادتهم ويصبحوا مستعدين للمضي بـاني

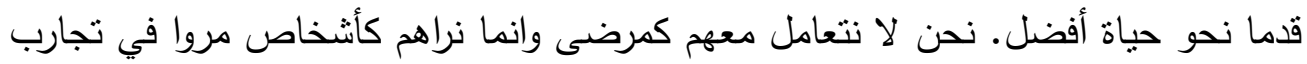

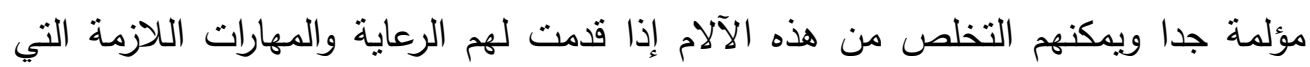
تهدف الى إعادة تأهيلهم من جديد".

المعالجة ليلى استخدت الاستعارة التالية لثرح وجهة نظرها حول تجربة مريض آخر حيث قالت: "هناك نباتات مدهشة تتمو وتتثق الصخر. تماماً منل الناس الذين يأتون إلى 
هنا، وهم على قيد الحياة رغم كل الصعاب ويزهرون ويتغيرون نحو الأفضل وهذا أمر

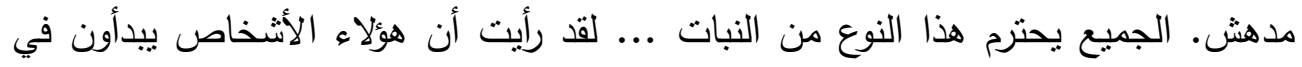
إحراز تقدم في شفائهم؛ وقد تطلب الأمر منهم الكثير من القوة ليتجاوزوا آلامهم، والكثثر منا لا يعترف بهم دائمًا".

عند التفكير في سبب عمل هؤلاء المُعالجين في هذا المجال بالتحديد، كان هناك

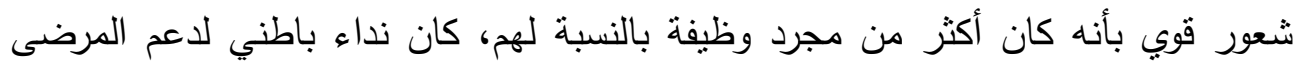

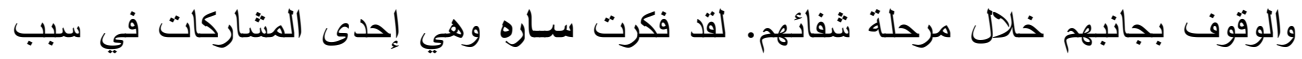

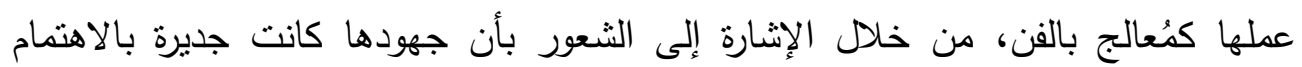
عندما رأت المرضى فخورين بأعمالهم في معرض الفنون العام والذي عُرضت فيت فيه أعمالهم

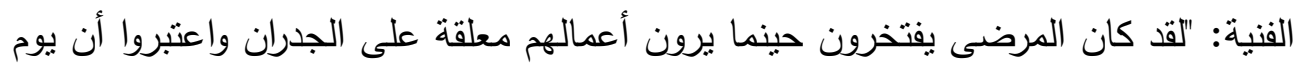
عروض أعمالهم الفنية هو يومهم بل أجمل أيام سنتهم. وحين كان رواد المعرض يتأملون

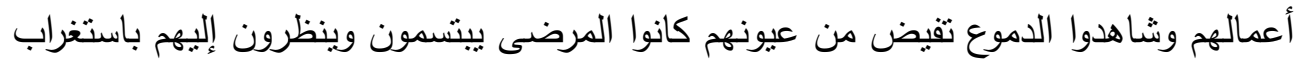
وكأن لسان حالهم يقول: نحن منلكم فلماذا تعابير وجوهكم حزينة واعينكم دامعة. وتعقب سارة بالقول: هذه أحد الأسباب التي دفعتتي الى تقديم خدماتي في الارشاد والتوجيه والتدريب

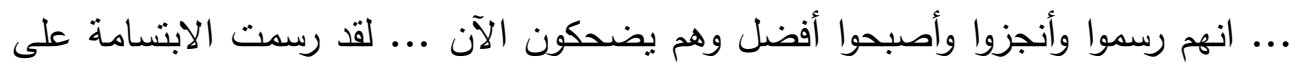

\section{المُعالج بالفن يخلق فرصا للتعليم والتتُلُم}

لقد استخدم المُعالجين الفنيين منهج مرن مرتكز على أن المريض يكون محور العملية

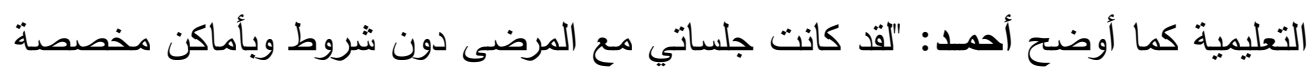
حيث لا توجد فرصه لأي شخص بأن يقاطعنا، وقد اعتمدت في تدريبهم على الأساسيات

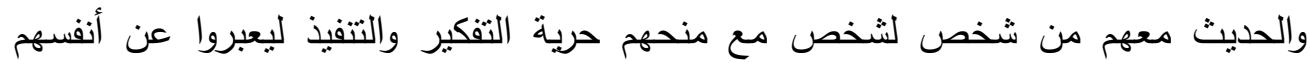

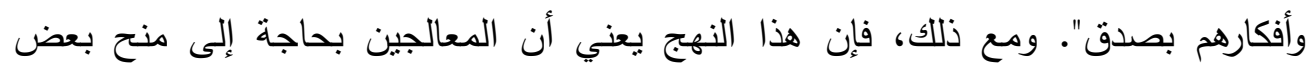

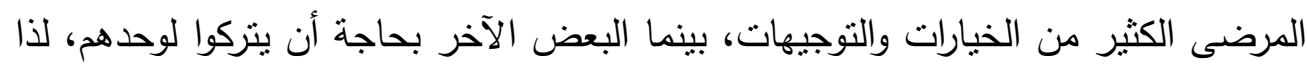
على المُعالجين بالفن مراقبة احتباجات كل مريض بشكل مستمر وجعله محوراً للتعليم والتعلم.

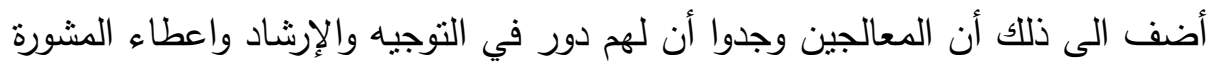
التقنية وتتمية المهارات الفنية، خاصة عندما لا يكون لدى المرضى الخبرة الكافية في الرسم 
او تطبيق تقنية معينة والخوف من ارتكاب الأخطاء. تقول سـاره في هذا المضمار : "في بعض الأحيان يكون من الصعب إخبار المرضى في البداية أنه سيتم التخلص من أعمالهم الفنبة في نهاية اليوم، كوسيلة لتخفيف التوتر والسماح للمرضى بالاسترخاء حتى تكون

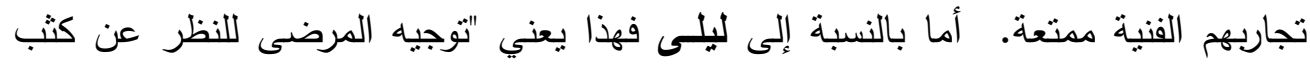

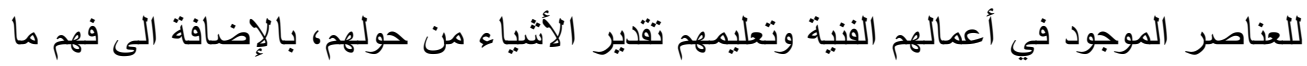
يمكن تحقيقه خلال تتفيذهم للأعمال الفنية ". لقد لاحظ جميع المعالجين بأن العديد من المرضى حضروا الى مجموعاتهم بحذر ألى وترقب تخوفا من الحكم على أعمالهم وعلى قدراتهم الفنية من قبل المعالجين، حتى أدركوا

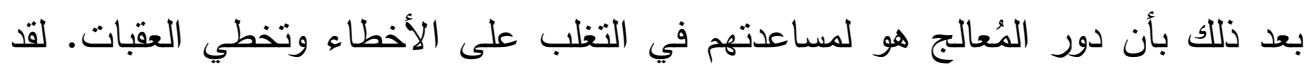

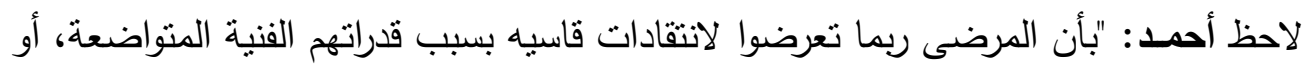

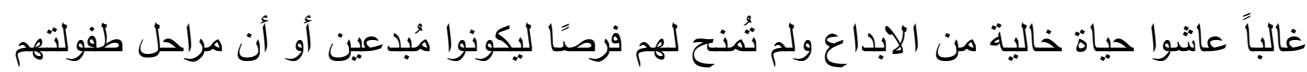

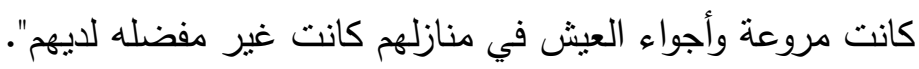

\section{المُعالج بالفن يوفر أجواء مُلائمة لتنفيذ الاعمال الفنية}

أكد المعالجون بالفن إن توفير الجو الملائم من الثقة والمحبة كان عامل جوهري لهنح المرضى فرص أكبر للتجريب واكتشاف العالم من حولهم. بهذا الخصوص قالت سارة: "لقد شجعت المرضى على اثارة الفوضى أثناء ممارسة الفن، وتحمل المخاطرة وتجريب أنشياء

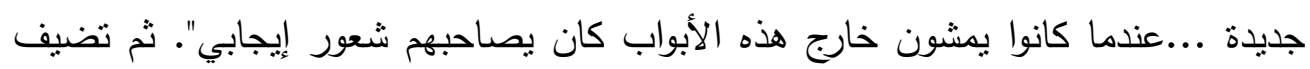

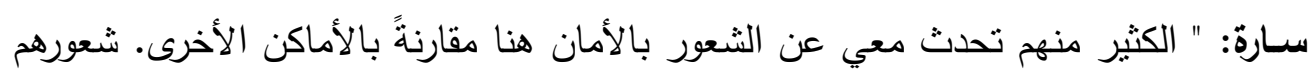
بالأمان ليس بالضرورة بسبب المكان؛ أعتقد أن الأمر بتعلق بمنحهم الثقة والاحترام وحرية التفكير والتعبير عن مشاعرهم بدون الحاجة للقلق من الانتقاد". بالإضافة إلى ذلك، كان الأمر يتعلق بخلق فضاء لا يشعرون فيها بالوحدة وشعورهم

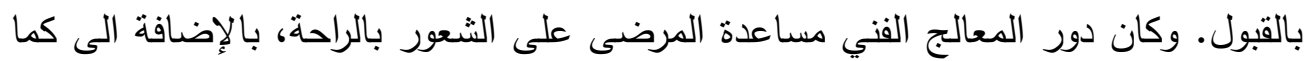

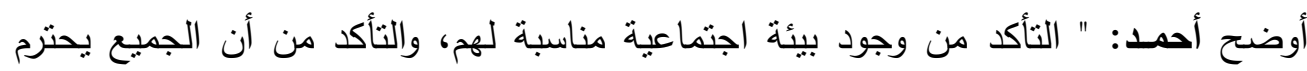
بعضه بعضاً... في كثبر من الأحيان المرضى يأنون إلى هنا لأسباب اجتماعية، لأنهم 


\section{r. الخصائص التحويلية باستخدام الفن كعلاج}

\section{المثابرة المصاحبة في انتاج الفن تخلق الثعور بالرضا والتفوق}

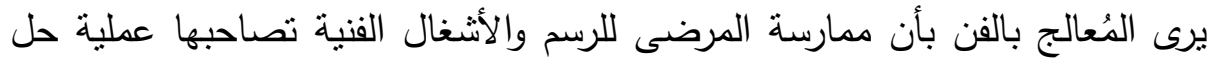

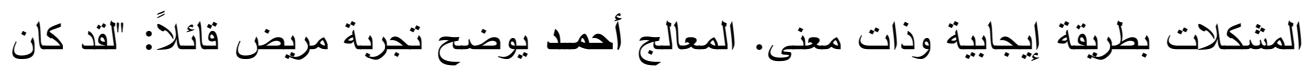

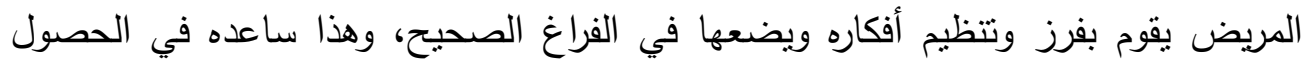
على وقفة للتأمل بهدف الحصول على نظرة شاملة والتي سمحت له بالتالي بتطبيق افكاره

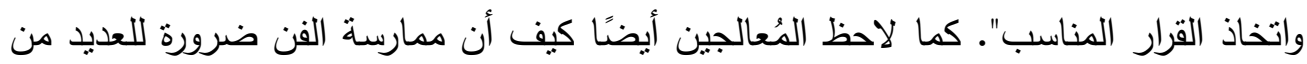
المرضى لتحرير الأمور التي تقلقه وإيجاد حلول لها. وحول هذا نوضح سـارة: "بأن كل شخص يمر بصدمة يذهب تلقائياً للبحث عن شيء أو عمل أثنياء معينه وهذه تكون وسيلتهم في حل مشكلاتهم. وقد تكون الصدمة مستمرة ولكن تبقى المحاولات مستمرة حتى لو تخلاه شيء من اليأس". وأوضحت كذلك "أن الفن يجعلك تمر بمراحل فوضى واحباط وعدم

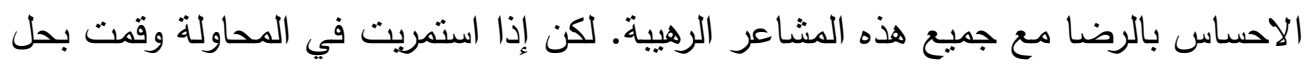

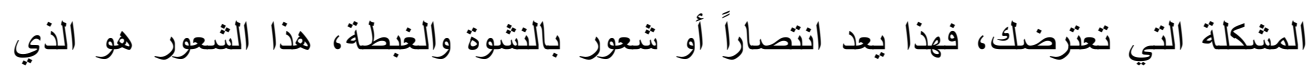

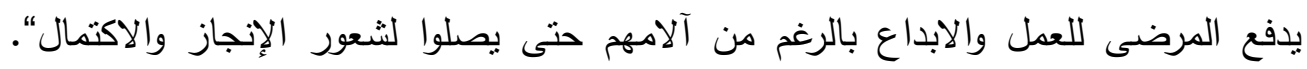

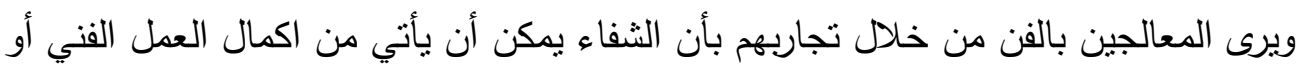

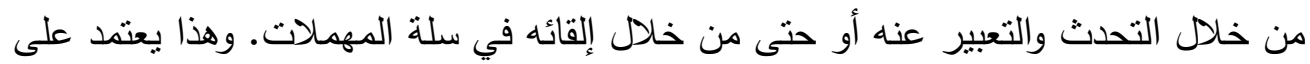
المريض نفسه ونوعية العواطف والمشاعر الملازمة له. ويظهر كذلك بأن الجزء الهام من عملية الثفاء مرتبط بالثعور بالرضى وتحرير المشاعر الملازمة لإنتاج العمل الفني، حيث

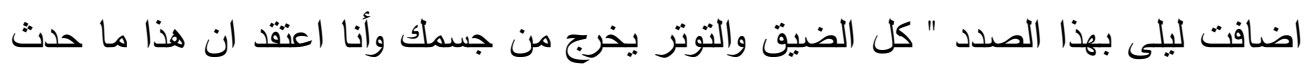
وهذه المشاعر بالتالي تتحول الى علاقات طبيعية مع الناس".

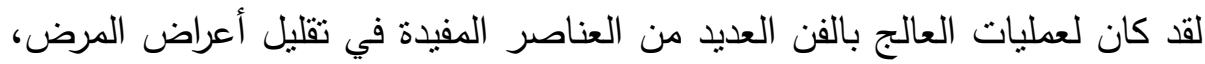

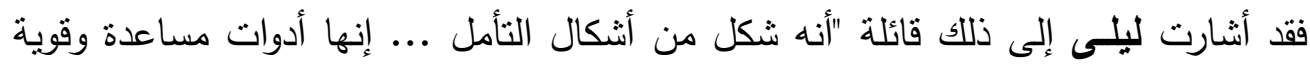
للتعافي وذات تأثير أفضل من العلاج الدوائي لأن المريض يصبح لايه القدرة على الانعزال

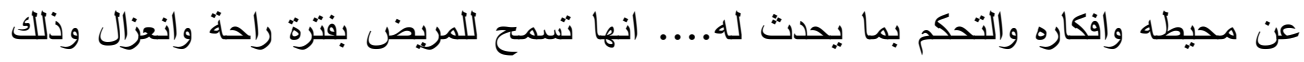
بايقاف أفكاره اثثاء ممارسة الفنون". كما أكد المُعالجين بالفن أن الاهتمام بالفن وممارسته لهُه يربط المريض بعالم آخر ويقوي العلاقات وقد وصفت ذلك ليلى بقولها "التواصل من خلال 
انتاج الاعمال الفنية يربط ذوي الاحتياجات الخاصة بما هو أعظم من آلامهم"، باعنبار أن

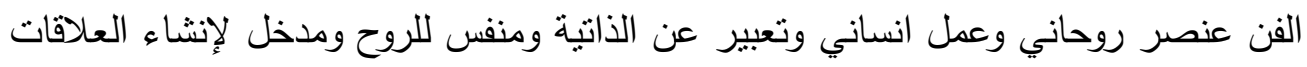

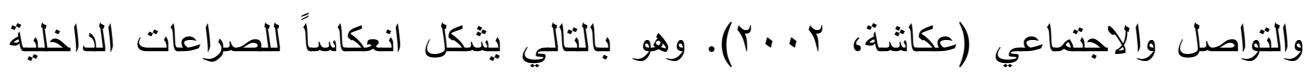
وإيجاد حلولا لها من خلال ممارسة المرضى للفنون.

العمل القني بمثابة انعكاس للأات يتقق المُعالجون بالفن بان العلاقة الناشئة بين المريض وعمله الفني تؤدي إلى معرفة

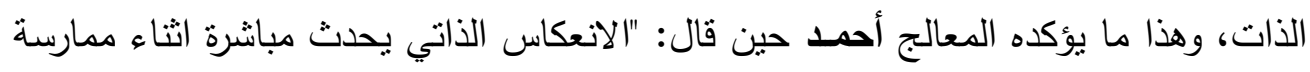

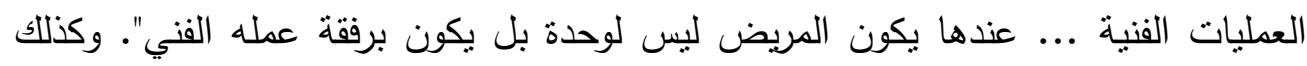

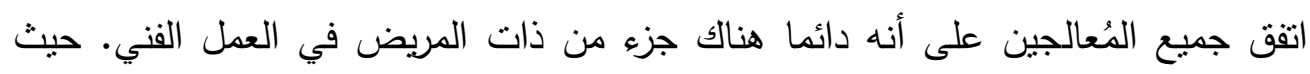

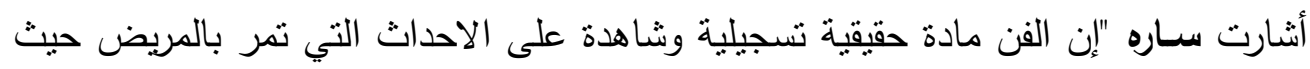

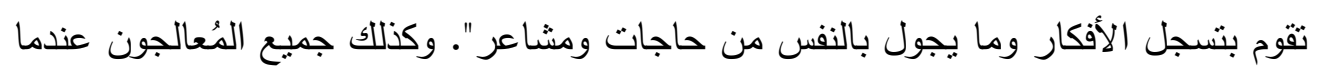

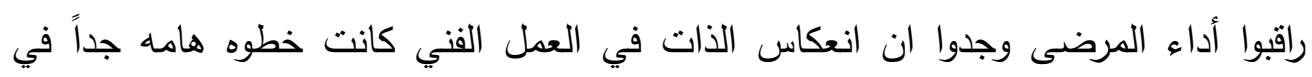

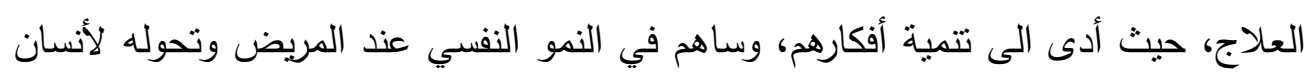

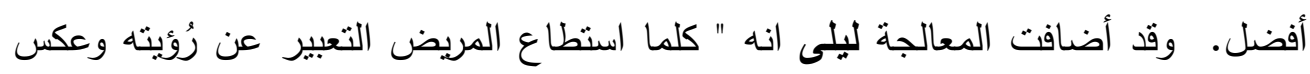

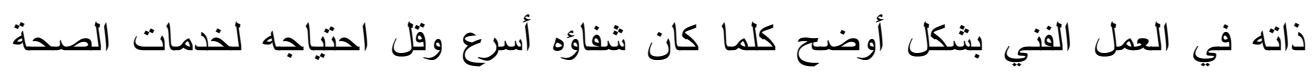

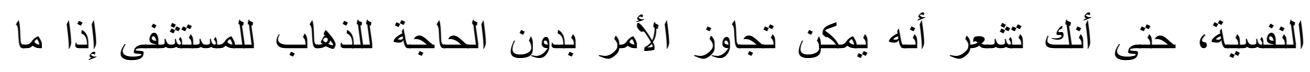
توافرت الأجواء المناسبة والدعم الازم لممارسة نشاطاته".

العمل الفني يساهم في التعبير عن الثعور وجوهر الذات

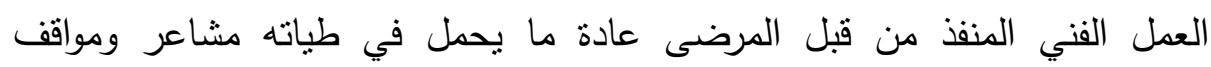

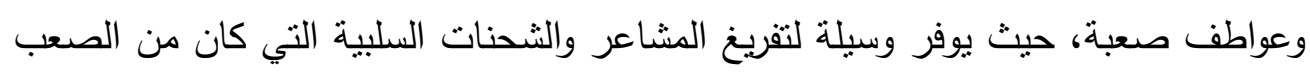

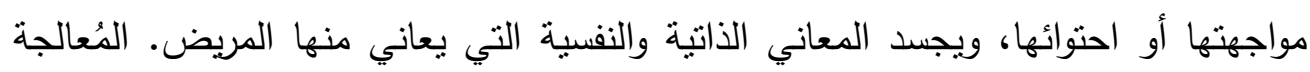

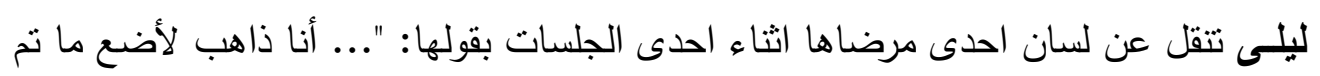

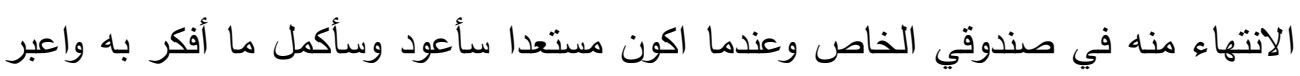

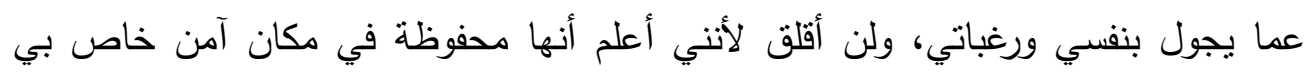


بالرغم من أنها ليست بحوزتي ... إن الأمر يتعلق بالقدرة على إخراج بعض هذه الأثياء

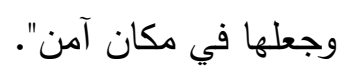

لقد ذكر المُعالجون بالفن بعض التجارب التي غيرت حياة المرضى، حيث وصفت

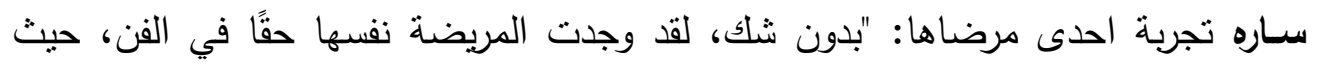
بدأت بالفعل بالنحت واستعاضت عن ايذاء نفسها بالسكين، باستخدام السكين ذاتها في تشكيل

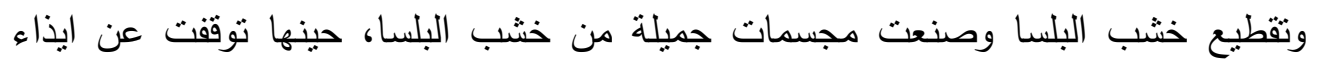
نفسها باستخدام فن تشكيل المجسمات". وأوضح المعالجون بالفن أيضا أن هذه التجارب الفنية يمكن أن نكون أكثر فعالية من التحدث للمرضى، حيث أن بعض ما قد يحتاج المرضى إلى التعبير عنه يتجاوز الكلمات. يقول أحمد في هذا المضمار : "يرسم المريض صورة ثم يفكر ويتأمل بها مرة أخرى ثم تثناهد

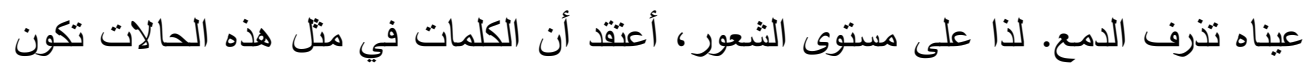
عاجزة عن التعبير عما يجول في نفسية المريض كاستخدام الفن كوسيلة للتعبير الذاتي". وتتفق سـاره مع أحمد حيث تقول: "التحدث مع المريض عادة يحرك الاثياء السطحية فقط دون الدخول الى أعماق الثعور عند المريض". تشير ليلى إلى احدى التجارب القوية التي تبرز دور الفن كوسيلة في التعبير عن

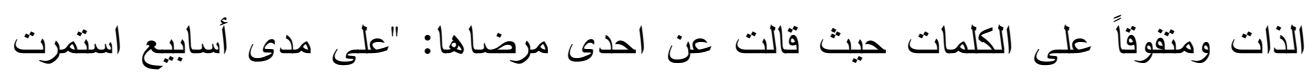

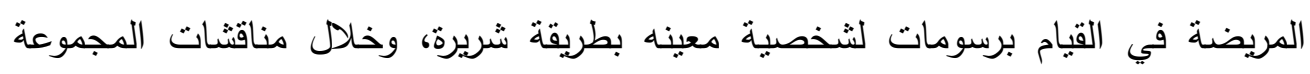

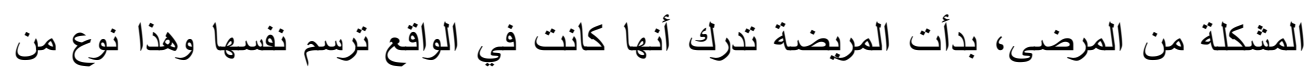

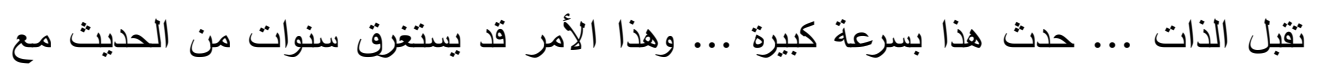
المريض للوصول لهذه النتيجة.

r. فوائسد الفن يتعدى الثعور الداخلي

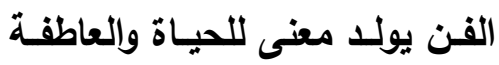

لقد لاحظ المعالجون بالفن حدوث تغيير كبير في الطاقة التي جلبها الفن إلى حياة

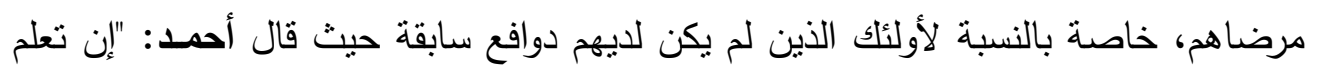
مهارة جديدة يمكن أن يحفز المريض مرة أخرى، وهذه المهارات المكتسبة تعده للمستقبل 
المهني". وقد أضاف أحمد: "إن وجود غرفة يتوافر فيها عدداً من الأعمال الفنية تعزز الخبرات والثقة عند المرضى. ومن منظور أحمد للفن قدرة على جعل الأثياء ينظر اليها ببساطة وتقدير والاستمتاع بها والتعلُم منها". وأوضح كذللك أنه من خلال ممارسة الفن: فانه عانه

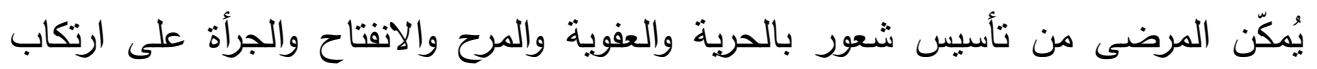

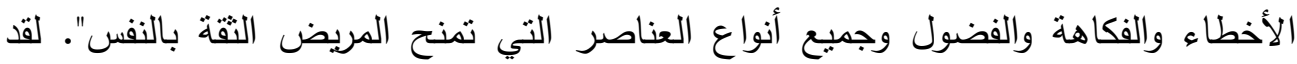

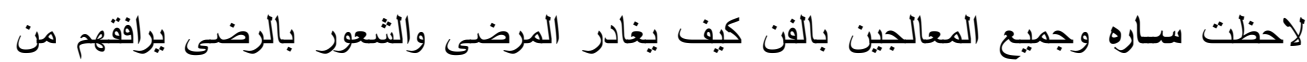

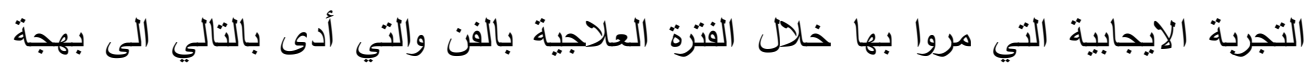
وشعور المعالجون بالرضى من النتائج التي حقوها.

\section{الفن يساعد على بناء علاقات مع الآخرين}

كان يُنظر إلى عملية ممارسة الفن على أنها وسيلة لتطوير الإبداع وتطوير الوعي، الوعين حيث أوضحت ليلى "أن انتاج وممارسة الفنون الابداعية أصبحت لها دوراً رائداً في الامور الحياتية الأخرى كتعلُم مهارات التفكير العليا وحل المشكلات". ولقد تعدت فائدة ممارسة الفنون في تطوير القدرات الإبداعية الى تكوين علاقات إنسانية مع الاخرين، حيث لوحظ ان

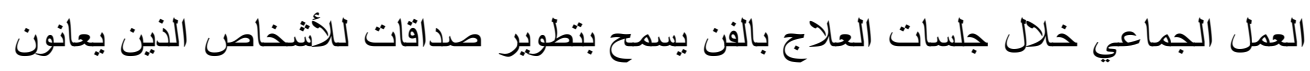

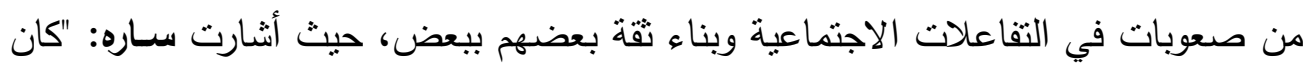
هناك الكثير من الصداقة الحميمة، وكان هناك الكثير من الثتعور الجيد والمرضى يثجعون

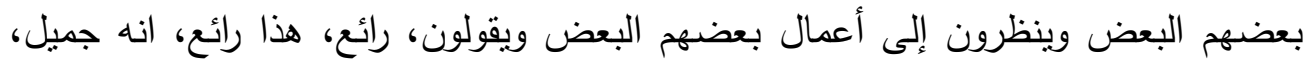
أتمنى أن أفعل ذلك". وقد لاحظوا أيضا أن الروابط التي تطورت خطان ألا هذه الجلسات كانت

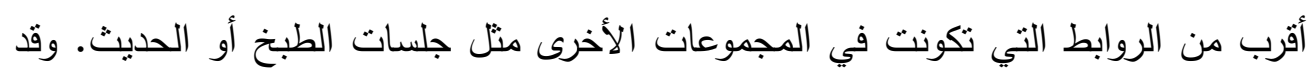

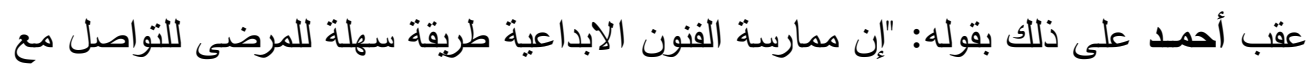
بعضهم البعض، لأنهم قد لا يشعروا بالراحة حول التحدث مع بعضهم البعض لكنهم يمكن لإنه التحدث مع بعضهم البعض من خلال عمليات تتفيذ الاعمال الفنية". 


\section{مناقشـة النتائسج والخاتمـة}

نتائج هذه الدراسة توفر بعض المفاهيم الجديدة لدور المشاركة في أنشطة الفن للعلاج

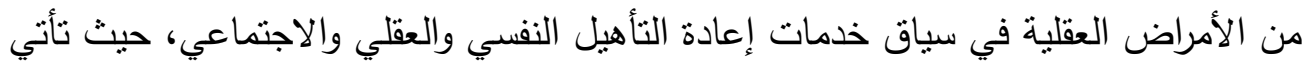
هذه المفاهيم من خلال استكثاف متعمق للخبرات والممارسات المتراكمة لعدد من المُعالجين بالفن من ذوي الخبرات. ويعتبر المُعالج بالفن في هذا القطاع مورداً غير مستغل في فهم هذه

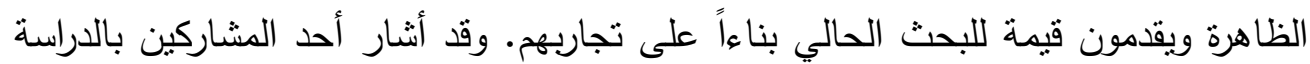
بأنه غالبًا ما يُنظر إلى هذا النوع من العمل على أنه موهبة ومهارة أكثر من كونه وظيفة.

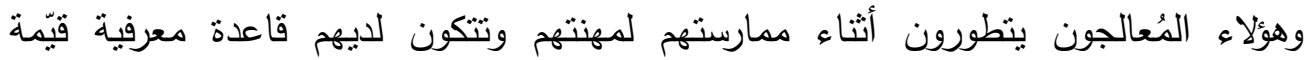
للمرضى واحتياجاتهم تساهم في عملية إعادة تأهيلهم. حيث قدموا رؤى غنية حول دورهم في موني عملية العلاج بالفن، ورحلة الثفاء وتأثثر الفن على إعادة التأهيل والتتمية الثخصية. وتماثشيا مع نموذج العلاج النفسي فقد رأى المُعالجون بالفن أن دورهم هو توفير الأهل

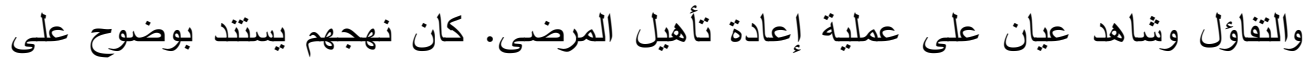
التقاليد الإنسانية التي تركز على إمكانات نمو الفرد، وكانوا شغوفين في إبراز قيمة نوفير

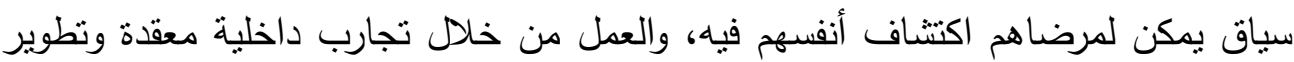

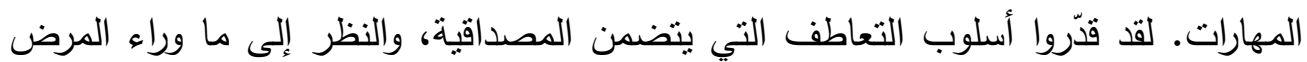
ورؤية الإبداع الفني المحتمل عند المريض. وقد اعتبرت السلوكيات الإيجابية جانبا أساسيا في تسهيل عملية إعادة التأهيل. حيث

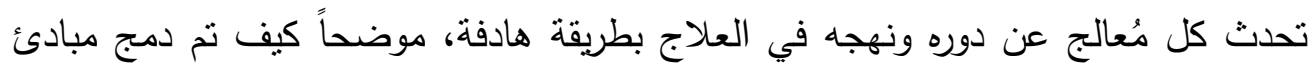

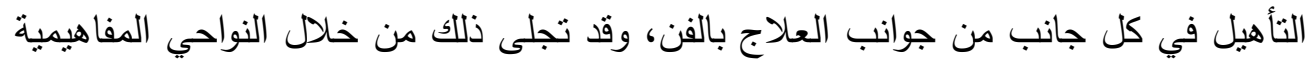

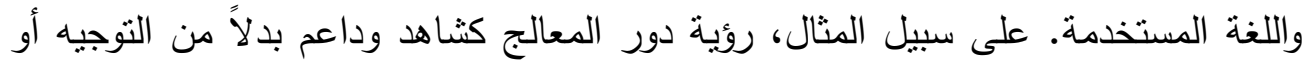

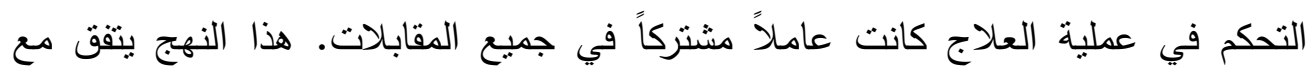
الفلسفة التي اوضحها كل من Eaton (2019) و (2018) Stickley والأمم المتحدة (10) والذي بسلط الضوء على التحول الإنساني الذي يحدث في تقديم خدمات الصحة

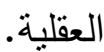

لقد تضمن دور المعالج مزيجًا من تتمية المهارات والدعم العاطفي والتوجيه والإرشاد خلال التحديات التي تواجه المرضى أثناء انتاج الاعمال الفنية وذلك اعتمادًا على احتياجات كل مريض. ولقد شملت عمليات التتفيذ كافة التفاصيل الدقيقة، منل أن يكون المعالج مدركًا 
للوقت الذي يجب أن يتدخل فيه ويساعد المريض ومنى يتركه لوحده. وهذا يتفق مع النتائج السابقة لهذه الدراسة التي بينت أن دور المُعالج يقوم على دعم المريض من خلال عمليات معرفة الذات عن طريق تشجيع الاتجاه الفردي الذاتي والسماح بالكثف عن حقيف دقيقة الفنان

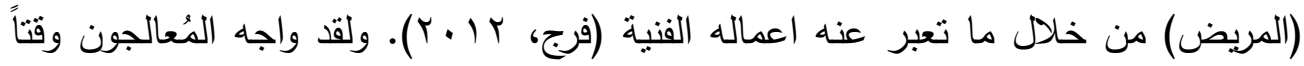
حرجاً عند بدء انضمام المرضى الى المجموعات الفنية، حيث لاحظوا أن المرضى بحاجة أنها إلى التشجيع والتحفيز حتى لا ينتقدوا أنفسهم ويحكموا على قدراتهم الفنية بالفشل مسبقاً.

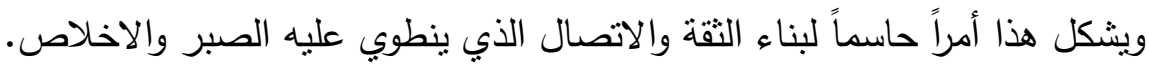

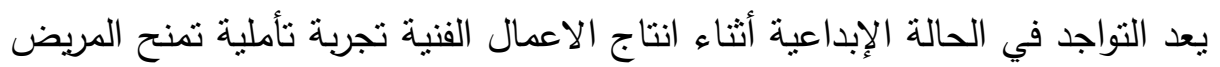
راحة من الاعراض التي يعاني منها. وهذا مشابه لحالة التجلي (Flow state) التي عرفها Csikszentmihalyi النمو النفسي وجودة الحياة والرفاهية. حالة التجلي لها أهمية خاصة بالنسبة لإنتاج الفن، والتي تتطلب المرونة بين الثعور واللاشعور من أجل تحويل المشاعر إلى ألفة واحتواء

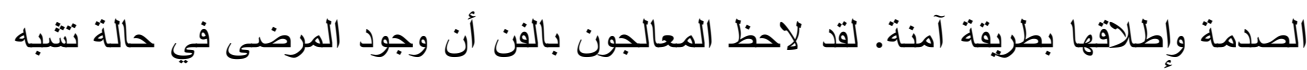

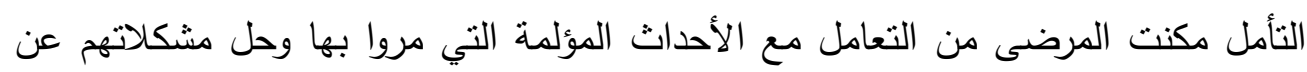
طريق التعبير عنها بالرسم والاثتال الفنية الأخرى حيث ساهم ذلك بالتتمية الذاتية والاحساس البصري (Warren, 2007).

لقد شعر المُعالجون بحاجة المرضى الماسة للحصول على منفذ للتعبير عن مشاعرهم الداخلية واستكثاف قضاياهم الثخصية، وقد توفر لهم ذلك خلال الرسم والاثغال الفنية حيث استطاعوا أن يعكسوا كل تجاربهم الحياتية في أعمالهم بأسلوب لم يكن متاح لهم بالطرق

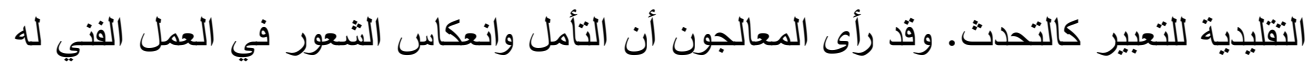
دور فاعل في ابراز المعنى والتعبير ودعم حل المشكلات والتتمية الثخصية. وفقًا لـ الكنجي

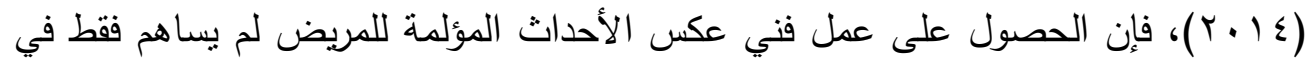
فهم تجربة المريض من خلال التعبير المرئي، ولكن العمل الفني قدم مرآة للنفس الداخلية.

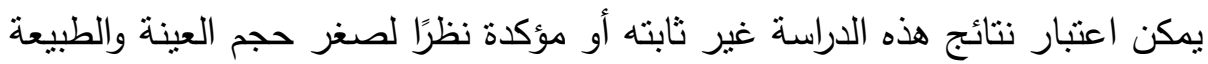

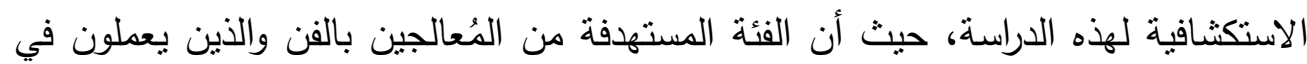
بيئات الصحة النفسية والاجتماعية صغير جدًا. وتكمن قوة الدراسة في البيانات الغنية المتعدقة والمكتسبة من هذه العينة. كما أن الانسجام والتطابق في النتائج التي توصل إليها 
المشاركين الثلاثة يعزز نتائج الدراسة، والتحقق من المواضيع مع المشاركين يعزز ايضاً من موثوقية النتائج. وتجدر الإثارة إلى أن المشاركين الثناثة جميعهم كانوا معالجين في مجال

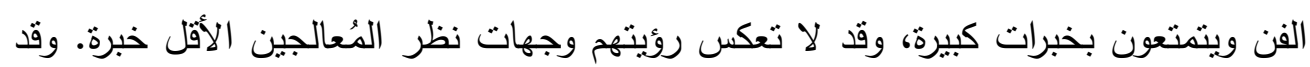

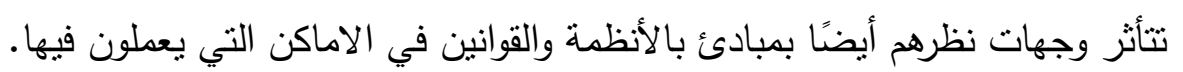

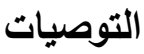

هدفت هذه الدراسة إلى نوفير أساس لتطوير الدفاهيم النظرية حول مساهمة الفن في عمليات إعادة التأهيل النفسي والعقلي • وهناك حاجة إلى مزيد من البحث لنطوير هذا الإطار

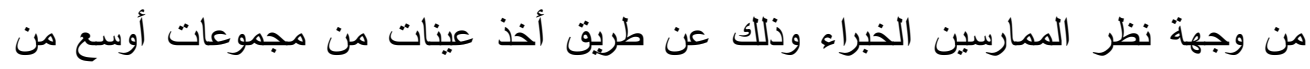

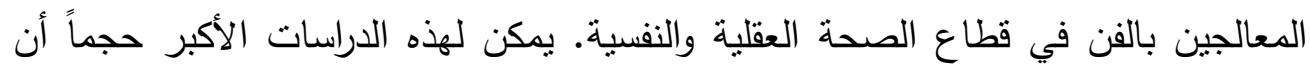
تصنع نموذجاً أولياً لدور ممارسة الفن في استعادة الصحة العقلية والنفسية، والسعي إلى تأكيد

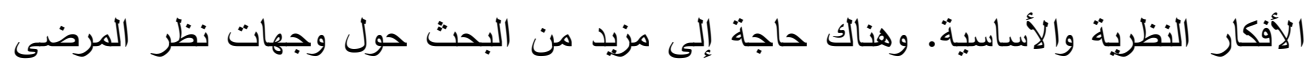

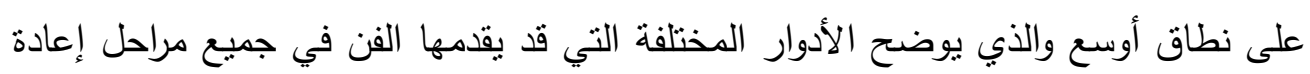
التأهيل النفسي المختلفة.

كذللك هناك حاجة إلى مزيد من الدراسات وتجريب مجالات مختلفة من ممارسات

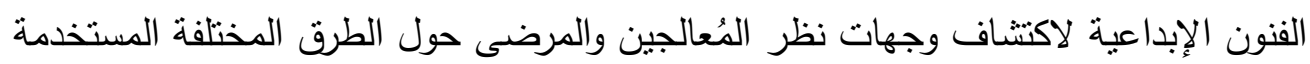

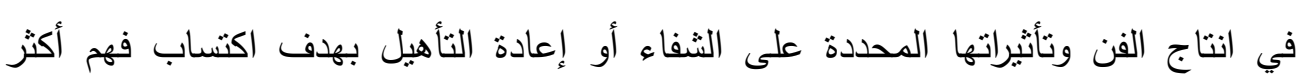

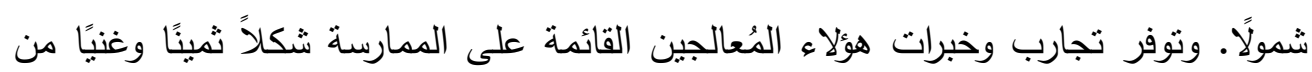
الأدلة العملية لإبلاغ خدمات إعادة التأهيل النفسي والاجتماعي وتدريب الموظفين. 


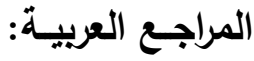

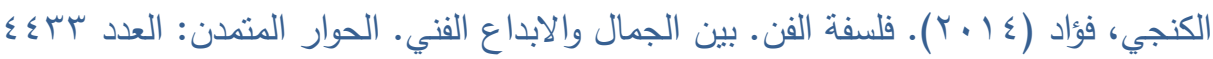
http://www.ahewar.org/debat/show.art.asp?aid=411768

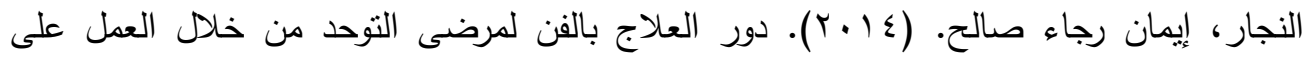

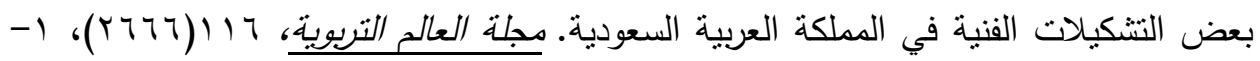

بوشالتر، سوزان (1 ( • (Y). العلاج بالفن: أنشطة عملية. ترجمة فريق دوبامين للخدمات النفسية والاجتماعية. مؤسسة يسطرون للطباعة والنشر . حمايدية، علي (T ( ا r). التكفل النفسي بالأمراض المستعصية بالوساطة العلاجية والعلاج بالفن.

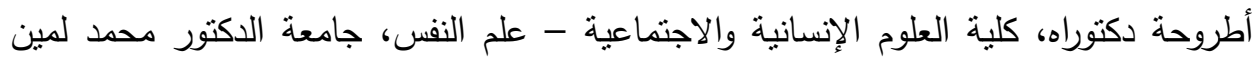
دباغين. الجزائر.

خطاب، محمد (Y (Y). العلاج بالفن لدعم النمو النفسي للأطفال ممن يعانون من اضطراب ضغوط ما بعد الصدمة: دراسة إكلينيكية. مؤسسة الدعم النفسي الاجتماعي، القاهرة. مصطفى، دينا (0 ( ب). العلاج بالفن والمهارات الاجتماعية للأطفال الذين يعانون من اضطراب

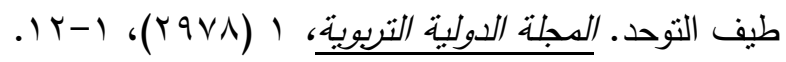
عكاشة، أنور (Y. . . . . الفن والحياة. دار الثروق، مصر

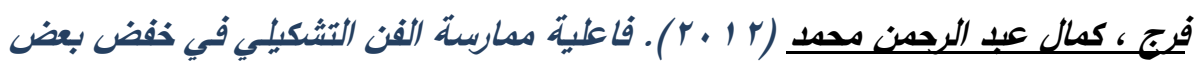
اضطربات السلولك لدى ذوي الإعاقة العقلية القابلبن للتدريب. دراسات علم النفس، العدد V،

$$
\text { IVP- } 121 \text { ص }
$$


American Psychiatric Association. (2031). Diagnostic \& statistical manual of mental disorders: DSM. V. TR. Washington DC: American Psychiatric Association.

Bertolote, J. (2008). The roots of the concept of mental health. World Psychiatry, 7 (2), 113.

Deegan, P. (2001). Recovery as self-directed process of healing and transformation. Occupational Therapy in Mental Health, 17 (3/4), 5-22.

Drennan, G., \& Alred, D. (Eds.). (2013). Secure recovery: Approaches to recovery in forensic mental health settings. Routledge.

Eaton, J. (2019). Human rights-based approaches to mental health legislation and global mental health. BJPsych international, 16 (2), 37-40.

Gehart, D. R. (2012). The mental health recovery movement and family therapy, part II: A collaborative, appreciative approach for supporting mental health recovery. Journal of marital and family therapy, 38 (3), 443-457.

Hyde, B., Bowles, W., \& Pawar, M. (2014). Challenges of recovery-oriented practice in inpatient mental health settings-the potential for social work leadership. Asia Pacific Journal of Social Work and Development, 24 (12), 5-16.

Karkou, V. \& Sanderson, P. (2006). Arts therapies: a research-based map of the field. Edinburgh. Elsevier Churchill Livingstone.

Khoury, E. (2018). The recovery perspective in assertive community treatment: how is it done and what does it mean to services users and service providers? Thesis and Dissertations. University of Montréal.

Lloyd, C., Wong, S., \& Petchkovsky, L. (2007). Art and recovery in mental health: A qualitative investigation. British Journal of Occupational Therapy, 70 (5), 207-214. 